\title{
Cartografía de la transformación de un territorio: La Araucanía 1852-1887¹
}

\author{
José Ignacio González Leiva ${ }^{2}$ y Patricio Bernedo Pinto ${ }^{3}$
}

\begin{abstract}
RESUMEN
La transformación territorial que tuvo lugar en La Araucanía entre 1852 y 1887, período que tardó el gobierno de la nación en incorporar este territorio al sistema de régimen interior que imperaba en Chile, fundado en el modelo provincial francés, es mostrada mediante una secuencia de cartas temáticas, con la que se pretende resaltar el valor de este tipo de representación cartográfica en la explicación de un hecho histórico que, como este, presenta una dimensión espacial. Los cambios territoriales que experimentó este sector del país tuvieron su punto de partida en 1852, luego de la creación de la provincia de Arauco, en la que a una parte de ella, la comprendida entre los ríos Biobío por el norte y Toltén por el sur, se le otorgó en primera instancia el estatus jurídico de "Territorio Fronterizo de la Provincia de Arauco", luego el de "Territorio de Colonización de Angol", hasta llegar finalmente a convertirse en las provincias de Malleco y Cautín en 1887, en el contexto de un proceso combinado de conquista y colonización.
\end{abstract}

Palabras clave: Cartografía temática, división política administrativa, provincias, colonización, organización territorial.

\begin{abstract}
The territorial transformation that took place in the Araucanía between 1852 and 1887, period which the government of the nation took to include this area his thin the political system in Chile, based on the French provincial model, is shown by a sequence of thematic maps, which aims to highlight the value of this type of mapping in explaining a historical fact, that like this our, has a spatial dimension. Administrative land changes experienced by this sector of the country had their starting point in 1852, after the creation of the province of Arauco, where a part of it that between, the Biobío river by the north and the Toltén by the south, was given in the first instance the legal status of "Border territory of Arauco Province", then the "Territory of Colonization of Angol", and finally to become the province of Malleco and Cautín in 1887, in the context of a combined process of conquest, and colonization.
\end{abstract}

Key words: Thematic cartography, administrative political division, province, colonization, territorial organization.

1 Proyecto FONDECYT 1051034, Representación cartográfica, ordenamiento político administrativo republicano, consolidación de la nación y desarrollo de Chile. Artículo recibido el 15 de diciembre de 2012, aceptado el 30 de diciembre de 2012 y corregido el 29 de enero de 2013.
2 Instituto de Geografía, Pontificia Universidad Católica de Chile (Chile). E-mail: jigonzal@uc.cl

3 Instituto de Historia, Pontificia Universidad Católica de Chile (Chile).E-mail: pbernedo@uc.cl 
La geografía histórica encuentra en la cartografía una muy buena aliada tanto para la interpretación como para la reconstitución del pasado, por el hecho que se trata de una herramienta que brinda múltiples posibilidades para representar y comunicar un fenómeno que ha tenido lugar en la superficie terrestre. Esta cualidad de la cartografía, es posible verla cumplida de mejor forma a través de la cartografía temática ${ }^{4}$, por la variedad de temas que en ella es dable abordar, en atención a su capacidad de mostrar gráficamente cualquier tipo de fenómeno que pueda ser localizado en el tiempo y en el espacio, ya sea este de naturaleza concreta o abstracta, de modo dinámico o estático, y en una dimensión cualitativa o cuantitativa.

Para mostrar los cambios político-administrativos que tuvieron lugar a mediados del siglo XIX en el territorio de La Araucanía, espacio localizado entre el río Biobío por el norte, el río Toltén por el sur, la cordillera de los Andes por el este y el océano Pacífico por el oeste, el utilizar una secuencia de cartas temáticas para seguir el desarrollo de este proceso, tiene todas las ventajas que ofrece la cartografía como medio de representación y comunicación.

Este proceso de cambios impulsado por el Estado de Chile en el territorio de La Araucanía, como veremos, se desarrolló en un contexto en el que confluyeron motivaciones de carácter estructural, como la necesidad de consolidar territorialmente la soberanía estatal en todo el país e integrar nuevas regiones al desarrollo económico nacional, con otras de carácter coyuntural, entre las cuales cabe mencionar algunos levantamientos indígenas; la posibilidad, aunque remota, de que La Araucanía se independizara y fuera dominada por una potencia extranjera; y el hecho que la elite política se inclinara finalmente por conquistar militarmente este territorio y someter a sus habitantes originarios.

\footnotetext{
4 La diferencia entre la cartografía topográfica y la temática es que mientras la primera representa los fenómenos que están de manera permanente en la superficie terrestre, en una dimensión planimétrica y altimétrica, en base a un levantamiento original y fundado sobre una proyección cartográfica, la segunda, se ocupa de la representación de los fenómenos localizables de cualquier naturaleza.
}

Las transformaciones que experimentó el territorio de La Araucanía, como resultado del afán del Estado chileno por incorporarlo al sistema de gobierno interior impuesto en el país luego de su desvinculación de España, se inició administrativamente en 1852, año en que tuvo lugar la creación de la provincia de Arauco por ley del 2 de julio, la que luego fue complementada por Decreto del Ministerio del Interior del 7 de diciembre del mismo año, en que se modificó su primitivo límite norte ampliándose hasta el río Laja. Al mismo tiempo, se creó en su interior el Territorio Fronterizo de Colonización de Arauco, área enmarcada por los ríos Biobío y Toltén, con un régimen especial de gobierno y administración.

En el camino que recorrió este espacio hasta su incorporación definitiva al territorio nacional, desde el punto de vista político administrativo tuvo lugar una serie de acciones de tipo político, económico y social, cuyo propósito, como veremos más adelante, estuvo destinado a la búsqueda de una solución militar al problema de los alzamientos mapuches (1851 y 1859) y también a la intención de incorporar esas fértiles tierras al desarrollo económico del país. Destaca entre otros, por su importancia y trascendencia, la implementación de un proceso de colonización que diferentes gobiernos impulsaron, así como también la propuesta de realizar una ocupación militar, asuntos que se intensificaron a partir del gobierno de José Joaquín Pérez (1861-1871). La percepción que reinaba en el ambiente nacional era la de una situación de desgobierno en La Araucanía y los medios de comunicación se encargaban de divulgar las diferentes posiciones que parlamentarios, habitantes del lugar y autoridades de gobierno tenían sobre el particular (Parentini y Herrera, 2003). Lo que allí ocurría fue descrito en 1854 por Domingo Faustino Sarmiento, quien afirmó que entre las provincias de Arauco y Valdivia, se intercalaba un territorio que no era una provincia y que aun podía decirse que no era Chile, ya que no flotaba su bandera y tampoco eran obedecidas sus leyes (Ravest, 2009).

La transformación de La Araucanía culminó, desde el punto de vista político administrativo, el año 1887, cuando a través de una ley del 12 de marzo, se crearon las provincias 
de Malleco y Cautín, situación que se alcanzó luego de haberse logrado la conquista y ocupación de La Araucanía en 1883.

Este proceso implicó un lapso de 35 años, en el que se transitó desde una figura jurídica representada por la de un "territorio fronterizo" en 1852, pasando por la de un "territorio de colonización de Angol" en 1875, para finalizar convertido en dos provincias, las de Malleco y Cautín, en 1887, las que a su vez fueron subdivididas en departamentos para su mejor administración.

La evolución y transformación de este territorio es el que se muestra a través de la secuencia de cartas temáticas, que permite y facilita comprender la acción del hombre sobre la superficie terrestre, en este caso para la adecuada organización del gobierno interior en La Araucanía.

\section{La provincia como unidad de organización territorial}

La forma de organización que se implementó en Chile como sistema de gobierno interior de la república, luego de las intendencias que había sido el modelo utilizado por la administración hispana en la gobernación de Chile, correspondió al de "la provincia", la que como unidad de base territorial se caracterizó por presentar cierta homogeneidad en su ámbito natural y cultural. Dicho modelo tuvo su inspiración en los "departamentos" franceses que se impusieron en esa nación luego de la Revolución de 1789. Aunque en los inicios del nuevo régimen la clase política francesa concibió como punto de partida el organizar el territorio de una manera ideal, como fue el implementar una división político administrativa de la superficie del país distribuida en 81 departamentos geométricamente cuadrados, pronto debieron optar por una división más acorde con la realidad histórica, política y geográfica que les imponía el espacio. Aunque esta no implicó una variación significativa en el número de departamentos, que aumentó a 83, sí generó cambios importantes en lo relacionado a su funcionalidad y a los criterios aplicados para la representación y proporcionalidad (Sanhueza, 2008). No obstante lo anterior, siempre se tuvo en cuenta que si bien dicha división debía responder a fines políticos y de administración por parte del gobierno, no debía olvidarse que lo que se estaba interviniendo era el territorio, asunto de especial importancia a la hora de valorar la forma de ejercer la acción política en el espacio.

Por su parte, los gobernantes de nuestro país estimaron que el éxito que había alcanzando la república gala en su desarrollo organizacional, así como en su posicionamiento en el concierto mundial, estaba en gran parte determinado por el patrón elegido para su administración interior, en razón a que este mostraba de manera inequívoca en el espacio uno de los principios básicos de la Revolución Francesa, el de "la igualdad", base fundamental además, para una adecuada representación política. Por cierto que el Estado chileno desde sus primeros intentos por darle forma a su administración, tuvo en mente establecer un régimen político con una adecuada representación de las provincias en el Poder Legislativo, pero también había conciencia que ello era primordial y necesario para facilitar e impulsar una eficiente organización territorial del espacio nacional.

El modelo francés consideró de manera significativa las condicionantes geográficas del territorio para la implementación de un equilibrado y armónico régimen político administrativo, asunto que en el caso de Chile tuvo elementos favorables para una delimitación y otros francamente perjudiciales. Entre los primeros estuvieron la presencia y disposición de las principales formas del relieve, que mantienen una orientación norte sur, como son la cordillera de la Costa, la Depresión Intermedia y por sobre todo, la cordillera de los Andes, elementos de gran ayuda al momento de imponer un criterio de horizontalidad. También el curso de los ríos, que se desplazan por lo general, con una dirección de oriente a poniente, resultaron ideales para delimitar espacios. Por el contrario, entre los segundos encontramos, entre otros, una marcada variabilidad climática, así como también de recursos naturales y poblacionales, situación que complica el definir áreas con características de cierta homogeneidad, objetivo que aunque no central, era al menos deseado en este tipo de política territorial. 


\section{Implementación del modelo provincial en Chile}

Siguiendo los principios de este modelo, el territorio bajo la jurisdicción del Estado chileno, emplazado entre el despoblado de Atacama por el norte y el cabo de Hornos por el sur, la cordillera andina por el este y el océano Pacífico por el oeste ${ }^{5}$, se fue parcelando de acuerdo a diversos requerimientos: a veces sociales, demográficos o económicos, pero en la mayoría de los casos ellos fueron de carácter político, en el más amplio sentido de la palabra. Fue un proceso que se llevó a cabo desde el centro del país hacia la periferia, con sucesivas subdivisiones de las primitivas tres grandes unidades territoriales existentes en los inicios de la república: Coquimbo, Santiago y Concepción, hasta llegar a disponer el país de veinticinco provincias a mediados del siglo XX, cuando en 1940 se creó la última unidad provincial, la de Osorno.

En 1826 se produjo la primera gran subdivisión, que se plasmó en la ley del 30 de agosto de ese año, cuando se crearon cinco nuevas provincias: Aconcagua, Colchagua, Maule, Valdivia y Chiloé, las que se sumaron a las tres existentes anteriormente, totalizando así ocho provincias. Aunque en la creación de estas nuevas unidades se definieron claramente sus límites, utilizando para ello el curso de los principales ríos o relieves de importancia como el cordón de Chacabuco, quedó en evidencia que todavía faltaba un real conocimiento de la geografía del país, situación que los sucesivos gobiernos se abocaron a resolver. Esto explica en gran medida la contratación del naturalista francés Claudio Gay en 1830, quien recibió el encargo de hacer un reconocimiento de la naturaleza que disponía la república y de manera muy especial, la ejecución de un levantamiento cartográfico de todo el territorio chileno. En esta misma dirección se enmarcó la posterior contratación en 1848, del geógrafo y geólogo francés Amado Pissis, a quien se le encargó, entre otras cosas, la confección de un Plano Topográfico y Geológico de Chile (González,

\footnotetext{
5 Límites fijados para el territorio chileno en los reglamentos y constituciones nacionales, a partir de 1812.
}

2007). En ambos levantamientos cartográficos, el territorio de La Araucanía careció de la suficiente información geográfica, lo que obedeció a la imposibilidad que tuvieron, tanto Gay como Pissis, para recorrerla y explorarla de manera sistemática, en especial el área ubicada entre la cordillera de $\mathrm{Na}$ huelbuta y la cordillera de los Andes, como consecuencia tanto de las dificultades que ponían los mapuches a los foráneos, como de las condiciones topográficas, climáticas y de la espesa vegetación del terreno.

De estos hechos dan cuenta ambos autores: Claudio Gay al informar en 1837 al Ministro del Interior, Ramón Luis Irarrázaval, del viaje que acababa "de hacer por la tierra de los indios de la costa", le manifestó que "sus intenciones eran de llegar hasta Llaima y Maquehua, pero sospechosos los (indios) de Tucapel de la naturaleza de mi viaje me impidieron el pasaje y me obligaron volver a Arauco" (Stuardo, 1975). Una situación similar se puede observar cuando el 11 de agosto de 1873, el Ministro de Educación de la época, al acusar recibo de un lote de las hojas del Plano Topográfico y Geológico a escala 1:250.000 que había enviado Pissis desde París, le preguntó del porqué la hoja $\mathrm{N}^{\circ} 11$ de esta serie, la correspondiente a La Araucanía, no había sido pintada con los colores por medio de los cuales se identifica la naturaleza y edad de los sustratos rocosos. Pissis respondió que ello se debía a que "esta hoja corresponde a la parte del territorio ocupado por los indios rebeldes y en la cual no ha sido posible penetrar" (Greve, 1946).

Cabe señalar que un progreso notable de la representación cartográfica del país en general y de esta área en particular, llegó años más tarde con el Mapa de Chile, a escala 1:500.000, elaborado por la Oficina de Mensura de Tierras, bajo la dirección de Luis Risopatrón, en 1910, con motivo del centenario de la república.

\section{Incorporación de La Araucanía al régimen de gobierno interior}

Desde los primeros momentos de la formación de la república de Chile, los gobernantes tuvieron conciencia que el control del territorio era la piedra angular para el 
ejercicio de la soberanía y, por lo tanto, el explorarlo, conquistarlo y reconocerlo era un asunto de primera importancia. En el caso de La Araucanía, durante la época colonial de la gobernación de Chile, ello no fue tarea fácil para los hispanos, al extremo que se acordó, luego de un parlamento en Negrete, presidido por el Gobernador de Chile Gabriel Cano y Aponte en 1726, que un accidente geográfico como el curso del río Biobío, fuese la línea de separación de las dos sociedades: la araucana y la española. La convivencia entre ellas estuvo jalonada por altos y bajos, donde los parlamentos sirvieron para mantener la paz, no obstante ella fue transgredida, en más de una ocasión, por alzamientos de los indígenas y la correspondiente respuesta militar de la gobernación, sucesos que con el advenimiento de la república no cesaron.

El estatus jurídico especial que los españoles le reconocieron a los mapuches, no solo implicó que se les otorgara el dominio efectivo de sus tierras, sino que además sus derechos fueran revalidados en el tiempo en distintos parlamentos, como el de Negrete de 1803. Lo anterior implicó, entre otros aspectos, que durante el desarrollo de las guerras de la Independencia, numerosos caciques mapuches otorgaran su apoyo a la causa del rey. Incluso, el carácter independiente de La Araucanía fue nuevamente confirmado por el general español Gabino Gaínza, en un parlamento celebrado con los mapuches en febrero de 1814. Allí, ellos revalidaron su compromiso de defender al rey español en caso de que este lo requiriera.

De esta manera, los mapuches al luchar contra las tropas patriotas no hacían más que respetar sus acuerdos con la Corona. Tampoco hay que olvidar que ellos veían en el triunfo de los patriotas un serio peligro para su condición de pueblo independiente, pues estos consideraban a La Araucanía como parte del territorio nacional chileno.

Con el alzamiento de 1835, bajo el gobierno de Joaquín Prieto, La Araucanía volvió a su fragilidad; sin embargo dicho acontecimiento tuvo el mérito de generar políticas para atraer a los naturales e incorporarlos a los usos civilizados, mediante parlamentos como el de 1838. En efecto, el período que va desde "1835 a 1859 fue de aproximación a los mapuches, permeado por una visión no beligerante influida sin duda, por la probada ineficacia de las armas como medio de doblegar su resistencia" (Ravest, 2009).

Sin embargo, más allá de algunos levantamientos ocasionales y geográficamente acotados, es posible afirmar que la situación en La Araucanía se mantuvo relativamente pacífica y sin mayores alteraciones durante el período que va desde la consolidación de la independencia en 1818 hasta la década de $1850^{6}$.

Por otra parte, los distintos estamentos de la sociedad chilena, como los políticos, el clero y los militares, tenían clara conciencia que la incorporación de La Araucanía a la república de Chile era un problema de Estado, motivo por el cual se requería de la participación de todos y cada uno de ellos para el logro de este objetivo. En 1848, la Cámara de Diputados encargó a Antonio Varas, en su condición de visitador judicial, un informe sobre la reducción pacífica del territorio araucano, donde se hiciera especial referencia a la conveniencia de establecer de una manera excepcional, la forma y el régimen de gobierno a implementar en las plazas fronterizas y territorios habitados por indígenas no reducidos (Varas, 1848). En su informe concluyó que había una serie de aspectos que podrían ayudar a alcanzar lo encomendado: en primer lugar consideraba, aunque con matices, que la convivencia entre la población mapuche y la chilena mostraba durante el último tiempo signos alentadores, siendo mejor esta relación con los mapuches de la costa que con los del interior. Sin embargo, esto no era garantía suficiente para que se intentara instalar cristianos en tierras habitadas por mapuches mediante la adquisición directa de sus terrenos, en atención al recelo que se generaba por los numerosos engaños que habían sufrido muchos de ellos anteriormente. Por ello, Varas sugirió que fuese el Estado el que comprara los terrenos a los mapuches para luego vendérselos a los particulares.

Por otra parte, ponderaba la buena acogida que tenían los sacerdotes misioneros dentro del pueblo mapuche, lo que hacía posible

$6 \mathrm{Al}$ respecto ver, entre otros, Villalobos (1982). 
utilizar este medio para llevar adelante una penetración pacífica mediante su instrucción, tanto en materia religiosa como de civilización?

En tercer término, la posibilidad de someter al pueblo mapuche a las normativas legales vigentes, como ocurría con el resto de la población que habitaba el país, la veía realizable a través de la presencia de una fuerza permanente en la frontera, importante en número, para mantener el respeto y evitar alzamientos, así como también aprovechando el buen entendimiento entre ambas comunidades, fruto de las relaciones establecidas por la práctica del comercio.

Finalmente, recomendaba establecer un régimen especial de gobierno solo en aquellos lugares donde fuese absolutamente necesario, como era el caso de La Araucanía, nombre que se le daba al área comprendida entre los ríos Biobío por el noreste y Taboleo por el noroeste, el Cautín por el sur, los Andes por el este y la cordillera de Nahuelbuta por el oeste.

Es en este contexto de toma de conciencia y valoración del problema por parte de las autoridades de la nación, el informe elaborado por Antonio Varas fue de gran importancia, especialmente en un momento en que se contaba con un ambiente favorable caracterizado por un período de relativa calma del pueblo mapuche.

En virtud de ello, el gobierno de Manuel Montt (1851-1861), estimó que estaban dadas las condiciones para la creación de una provincia en La Araucanía, asunto que se concretó con la promulgación de la ley de 2 de julio de 1852, mediante la cual se creó la provincia de Arauco. Sus límites se fijaron en los ríos Carampangue, Taboleo y Biobío por el norte, el río Toltén por el sur, el océano Pacífico por el oeste y la cordillera de los Andes por el este. El 7 de diciembre de ese mismo año, por Decreto del Ministerio del Interior, se amplió el territorio provincial

\footnotetext{
7 Respecto a las tareas misioneras entre los mapuches, ver Noggler (1982). Cabe señalar que la Iglesia Católica se opuso tenazmente a lo que denominó el "exterminio" de los araucanos. Al respecto, consul$\operatorname{tar}$ (Pinto, 2003).
}

por el norte hasta el río Laja, dentro del cual quedó comprendido un espacio denominado Territorio Fronterizo de la Provincia de Arauco, emplazado entre los ríos Biobío y Toltén. Este espacio quedó bajo el mandato directo del Presidente de la República (Varas, 1848). Esta particular figura jurídica que se estableció para su gobierno y administración, denota que se tenía en consideración el hecho que se trataba de un área diferente al resto del país por condicionantes de tipo histórico, político y geográfico, pero en lo esencial por las particularidades de la población que lo ocupaba (Figura $\mathrm{N}^{\circ} 1$ ).

No obstante lo anterior, las autoridades del gobierno tuvieron en mente ejercer el poder sobre todo el territorio nacional de manera homogénea, lo que a juicio de A. Núñez respondió "a la lógica de la uniformidad, que se dispuso, en el fondo, como una cuestión de racionalización inevitable" para añadir luego que "la organización nacional, en tanto formación moderna, fundaba sus bases en la territorialidad como uno de los principios rectores. La territorialidad consolida los valores nacionales y viceversa", para concluir que en el caso de Chile "el proyecto unitario de administración territorial, fue uno de los aspectos donde más claramente se observó el desarrollo del nuevo Estado para organizar y construir una nación cuya herencia precisamente había sido lo contrario: la desintegración y que se hace notorio cuando se analizan los emprendimientos bélicos, ya sea al norte o al sur, con el fin de consolidar territorios, con fines de extensión productiva, lo que para el caso de La Araucanía ha sido llamado "ampliación de las fronteras productivas" (Núñez, 2010: 172). En definitiva se trata de una forma más de ejercer el poder por parte del Estado en el territorio bajo su jurisdicción.

Con todo y aunque el gobierno creó la provincia de Arauco y definió sus límites, el conocimiento de las condiciones geográficas de La Araucanía era muy deficiente, resultado lógico de la imposibilidad de haberla explorado y generado información de estas materias, así como también por la falta de levantamientos cartográficos confiables. Esta situación influiría de manera decisiva en los problemas que debió enfrentar posteriormente el ejército en su avance al sur del río 
Figura $\mathrm{N}^{\circ} 1$

Representa la provincia de Arauco comprendida entre los ríos Laja por el norte y Toltén por el sur y, dentro de ella, el Territorio Fronterizo de la Provincia de Arauco. Situación correspondiente a diciembre del año 1852.

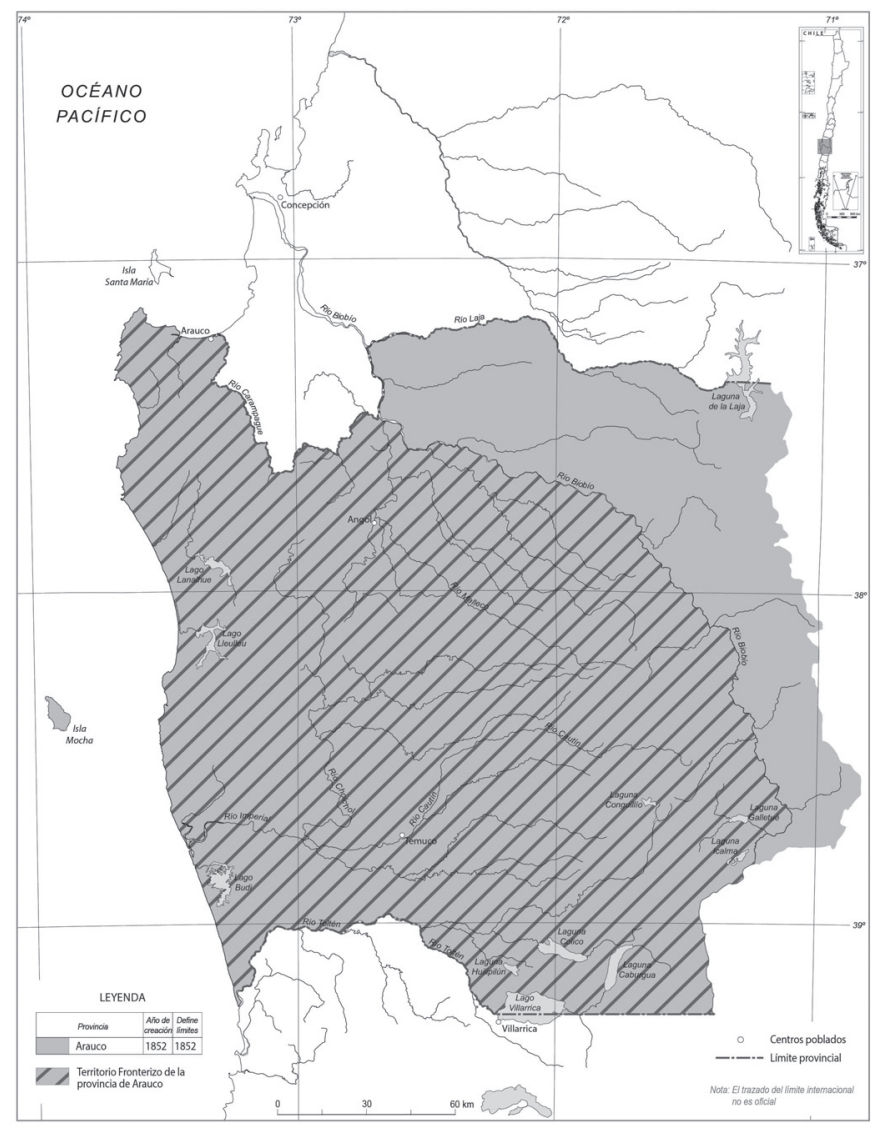

Fuente: Proyecto FONDECYT 1051034.

Biobío, cuando se inició la ocupación de este territorio, misión que se le encomendó en 1861 al teniente coronel Cornelio Saavedra. Proceso largo y lento, que Manuel Ravest describió de la siguiente manera: "La pacificación, reducción, conquista u ocupación de La Araucanía, concluida en 1883 en Villarrica, tomó veinticuatro años si los contamos desde el frustrado intento de 1859. Recomenzada en 1861, demoró seis años en llegar al Malleco, siete más adelantarla al Traiguén, y cuatro más alcanzar el Toltén para custodiar los boquetes andinos y cerrar así el cuadrilátero araucano (Biobío-Toltén-Pacífico-Andes)" (Ravest, 2009).
El cambio de estrategia de las autoridades puede explicarse, entre otros aspectos, debido a que las relaciones entre el gobierno chileno y los mapuches se comenzaron a deteriorar cuando estos, en el contexto de las revoluciones de 1851 y 1859 , atacaron algunos poblados en las cercanías de Concepción, “(...) con agregado de que entonces los indígenas se deshicieron de muchos colonos establecidos al sur del Biobío, que les habían quitado sus tierras con buenas o malas artes o por la fuerza" (Villalobos, 1982).

Cabe señalar que la participación de los mapuches en ambas revoluciones también 
tuvo un carácter político-estratégico, en el sentido que veían el debilitamiento del gobierno central como la única posibilidad de evitar que sus territorios fueran conquistados (Bengoa, 1996).

Sin embargo, la decisión de incorporar La Araucanía al territorio nacional se apresuró -y también se utilizó como excusa- con la aparición, en 1861, de un aventurero francés, Orélie Antoine de Tounens, en dicha zona. Tras ganarse la confianza de los mapuches, este personaje se hizo proclamar rey de La Araucanía, bajo el nombre de Orélie Antoine I.

Ante el riesgo de que el territorio fuera controlado por alguna potencia extranjera o que efectivamente lograra independizarse, el gobierno tomó cartas en el asunto y al poco tiempo el francés fue capturado por tropas chilenas y recluido en una casa de orates. En 1862 fue entregado al gobierno francés y enviado de regreso a su patria (Bengoa, 1996).

A lo anterior, debe agregarse como un factor explicativo importante de la conquista de La Araucanía, la convicción de una parte significativa de la elite capitalina -apoyada profusamente a través de la prensa- de que este territorio, rico y fértil, debía ser incorporado a la soberanía del Estado chileno y al desarrollo económico del país (Parentini y Herrera, 2003). Al respecto, un corresponsal de El Mercurio expresó en 1859 desde Valdivia: “(...) Se trata de formar de las dos partes separadas de nuestra República un complejo ligado; se trata de abrir un manantial inagotable de nuevos recursos en agricultura y minería; nuevos caminos para el comercio en ríos navegables y pasos fácilmente accesibles sobre la cordillera de los Andes" 8 .

La fórmula elegida por parte del gobierno central del cómo incorporar el territorio de La Araucanía bajo el imperio de la ley chilena, tuvo como primer paso el de la conquista y luego la ocupación, en la que ciertamente, como en todo proceso de esta naturaleza, hubo excesos tanto por parte de los que se

\footnotetext{
8 "Valdivia. Correspondencia de El Mercurio. Una cuestión de importancia", 5 de julio de 1859, citado en Parentini et al., 2003: 105.
}

introducían en el territorio como de los que resistían a tal incursión. Ante la opción elegida por el gobierno para llevar adelante su propósito, surgieron voces que aprobaron la estrategia a seguir y otros que la rechazaron. Partidarios fueron entre otros, Aníbal Pinto, Domingo Santa María y Benjamín Vicuña Mackenna; detractores, Manuel Antonio Matta y José Victorino Lastarria, quienes junto a otros parlamentarios se opusieron al aumento de tropa para defender la línea del Malleco, cuando el ejército había logrado llegar hasta este punto ${ }^{9}$.

De este lento pero constante proceso de avance, fue dando cuenta la incorporación de nuevos espacios al ámbito territorial de la provincia de Arauco. En efecto, ya en 1854 se le había traspasado parte del departamento de Lautaro de la provincia de Concepción, aquel comprendido desde la desembocadura en el mar del río Laraquete, la cordillera de $\mathrm{Na}$ huelbuta y hasta el río Carampangue, sector donde sus habitantes, como en general había sido la tónica de la costa de La Araucanía, mostraba una mejor disposición a relacionarse con los "chilenos", en especial por medio del intercambio comercial que era cada día más frecuente y donde también habían sido aceptados de buena manera el accionar de las misiones religiosas (Figura $\mathrm{N}^{\circ} 2$ ).

\footnotetext{
9 Durante los meses de agosto, septiembre y octubre de 1868, la Cámara de Diputados analizó un proyecto enviado por el Ejecutivo que solicitaba aumentar 1.500 hombres en el ejército de Arauco e invertir 500.000 pesos en la continuación de aquellos trabajos, el que finalmente se aprobó. En la sesión del 8 de agosto, el diputado Matta manifestó que la actitud tomada por el gobierno "contra los indios era contraria a la justicia" y que los resultados eran contrarios a los prometidos; "que la ocupación pacífica traía por resultado la conquista por la resistencia de los indios"; "que la conquista podía ser fácil pero no razonable y que era, además, peligroso poner un crecido número de fuerzas en manos de un hombre en medio del desgobierno y del desorden". Por su parte, el diputado Vicuña Mackenna, en la sesión del 9 de agosto, opinó "que los indios no son reducibles por vías únicamente pacíficas; que no merecen las mismas consideraciones que los pueblos civilizados; que solo por la escasez de recursos y la debilidad de nuestra parte, ellos podían subsistir; que todos están de acuerdo en que debe obrarse de una manera enérgica y sistemática, con recursos suficientes". Para concluir afirmando: (...) "no sea que paguemos en sangre lo que pretendemos ahorrar en oro" (Saavedra, 2003: 371-373).
} 
Figura $\mathrm{N}^{\circ} 2$

Registra la primera incorporación de territorio a la provincia de Arauco en 1854, correspondiente a la parte sur-oeste del departamento de Lautaro que hasta entonces formaba parte de la provincia de Concepción. Permanece invariable el Territorio Fronterizo de la Provincia de Arauco, entre los ríos Biobío y Toltén.

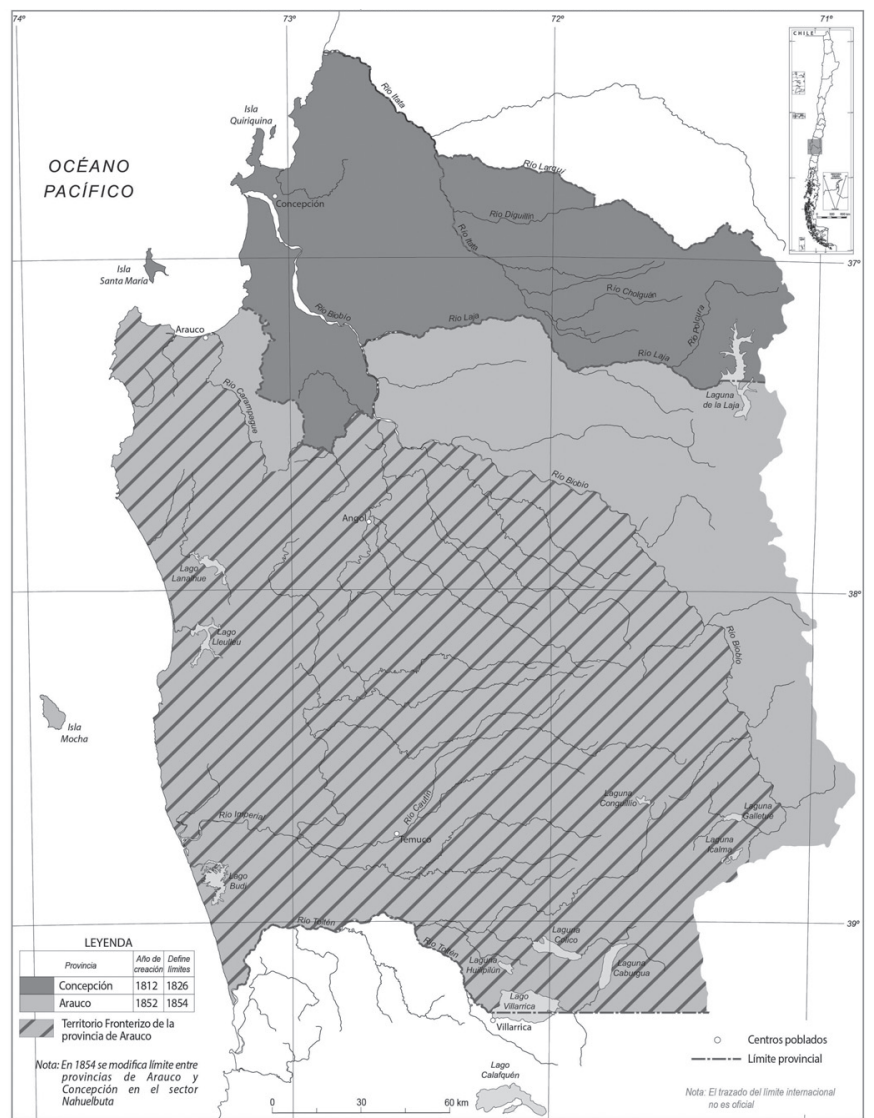

Fuente: Proyecto FONDECYT 1051034.

\section{La ocupación efectiva de La Araucanía}

En la época que tuvo lugar la creación de la provincia de Arauco (1852), la distribución y composición de la población en La Araucanía, posibilita distinguir al menos tres áreas claramente diferenciadas en función del predominio y concentración de sus habitantes a lo largo y ancho de su territorio. Por una parte, están aquellas donde la incorporación de los afuerinos a las comunidades araucanas había sido más relevante, como las corres- pondientes a la alta y baja frontera, es decir, en el Ilano que va desde el río Biobío hasta el río Malleco y en la ubicada al oeste de la cordillera de Nahuelbuta, respectivamente. En ambas se registró un predominio de chilenos por sobre los mapuches, cuya actividad primordial era la agricultura. Por la otra, se encuentra la zona emplazada entre los ríos Cautín y Toltén, donde la supremacía era de los mapuches, cuya principal actividad era la ganadería. Estas condicionantes tanto demográficas como económicas, fueron factores esenciales para la creación de unidades político-administrativas menores como los 
departamentos, destinadas a darle sustento a la organización territorial que se deseaba implementar en el área a medida que se avanzaba en su ocupación.

Bajo el gobierno de José Joaquín Pérez (1861-1871), se dio un nuevo impulso a la política de conquista militar de La Araucanía, y como se dijo anteriormente, se estimó oportuno poner en ejecución el plan que había propuesto el coronel Cornelio Saavedra durante el gobierno de Manuel Montt. Este plan consideraba en líneas generales el traslado de la denominada línea de la frontera desde el río Biobío al río Malleco, área que sería protegida por la construcción de una serie de fuertes junto con la venta de terrenos a población no indígena para aumentar la densidad poblacional y reforzar la penetración por medio de colonos en el mundo mapuche. Para la implementación de este plan era fundamental la ocupación de los suelos de mejor calidad para facilitar el asentamiento de la población y el desarrollo de las labores agrícolas de los nuevos habitantes, así como también para la instalación de puestos de vigilancia y defensa. Como consecuencia de lo anterior, se fundaron en 1862 las localidades de Mulchén, Angol y Lebu, y se levantaron los fuertes de Collipulli en 1867, Cañete en 1868, y Purén y Lumaco en 1869.

Como resultado del proceso de penetración y colonización que llevaron adelante los diferentes gobiernos, la consecuencia directa de ello fue el traslado de la línea de la frontera al sur del río Biobío, a pesar de la ocurrencia de levantamientos indígenas como el de Angol de 1868. Dada las características de la ocupación del territorio, especialmente de aquel ubicado entre el río Malleco por el norte y el Toltén por el sur, este tuvo un régimen de administración diferente al que imperaba en el resto de la república, el que por ser destinado a la colonización, sus autoridades eran militares y dependían única y directamente del Presidente de la República.

Durante la década de 1860 se crearon distintos departamentos en la zona, accionar que refleja el interés de las autoridades de gobierno de ir imponiendo también en La Araucanía el régimen de gobierno interior que imperaba en el resto del país. En efecto, en 1863 se fijaron los límites de los departa- mentos de Arauco (capital Lebu) y Nacimiento (capital Nacimiento), los que se ubicaron en el sector occidental de la provincia de Arauco, hecho que implicó la disminución de la superficie del Territorio Fronterizo de la Provincia de Arauco (Figura $N^{\circ} 3$ ). Posteriormente, en 1869, se definieron los límites de los departamentos de Angol (capital Angol), Lebu (capital Lebu) e Imperial (capital Toltén). La definición de los límites de estos últimos tres departamentos trajo como consecuencia la reducción del territorio del departamento de Arauco, así como también del espacio del Territorio Fronterizo de la Provincia de Arauco, que pasó a denominarse Territorio de Colonización de Angol (1875), cuyos límites eran coincidentes con el Departamento de Angol (Figura $\mathrm{N}^{\circ} 4$ ).

La consolidación del avance registrado al sur del río Biobío posibilitó que por ley del 13 de octubre de 1875 se creara la provincia de Biobío, emplazándosela en el noreste de La Araucanía. Se le fijaron como límites: al norte, el río Laja; al sur, el río Renaico; al oeste la provincia de Arauco y al este la cordillera de los Andes, lo que en el hecho consolidó el traslado de la primitiva provincia de Arauco hacia el litoral. De este modo, la nueva provincia de Arauco quedó ubicada en el oeste y sur de La Araucanía, sector que se había mostrado hasta el momento, menos belicoso con las incursiones de los chilenos. Limitaba al norte con el golfo de Arauco y por el sur con la desembocadura del río Lingue o Mahuín, siguiendo el curso de este río hasta su nacimiento en el cordón de Mahuidanche, para unirse con el río Cruces hasta empalmar con el lago Villarrica y culminar en la cordillera de los Andes. Cabe señalar que por el sur incorpora una franja de territorio al norte y sur del río Toltén ( $\mathrm{Fi}$ gura $\mathrm{N}^{\circ} 5$ ).

En la medida que se fue consolidando el proceso de penetración mediante la acción militar y el asentamiento de población en diversas localidades, las provincias de Biobío y Arauco fueron subdividiéndose en departamentos, por medio de la creación y definición de sus límites, así como también por medio de la anexión de otros ya existentes. En efecto, al establecerse la provincia de Biobío en 1875, se crearon al mismo tiempo los departamentos de Laja y Mulchén, a los 
Figura $\mathrm{N}^{\circ} 3$

Territorio Fronterizo de la provincia de Arauco, 1863.

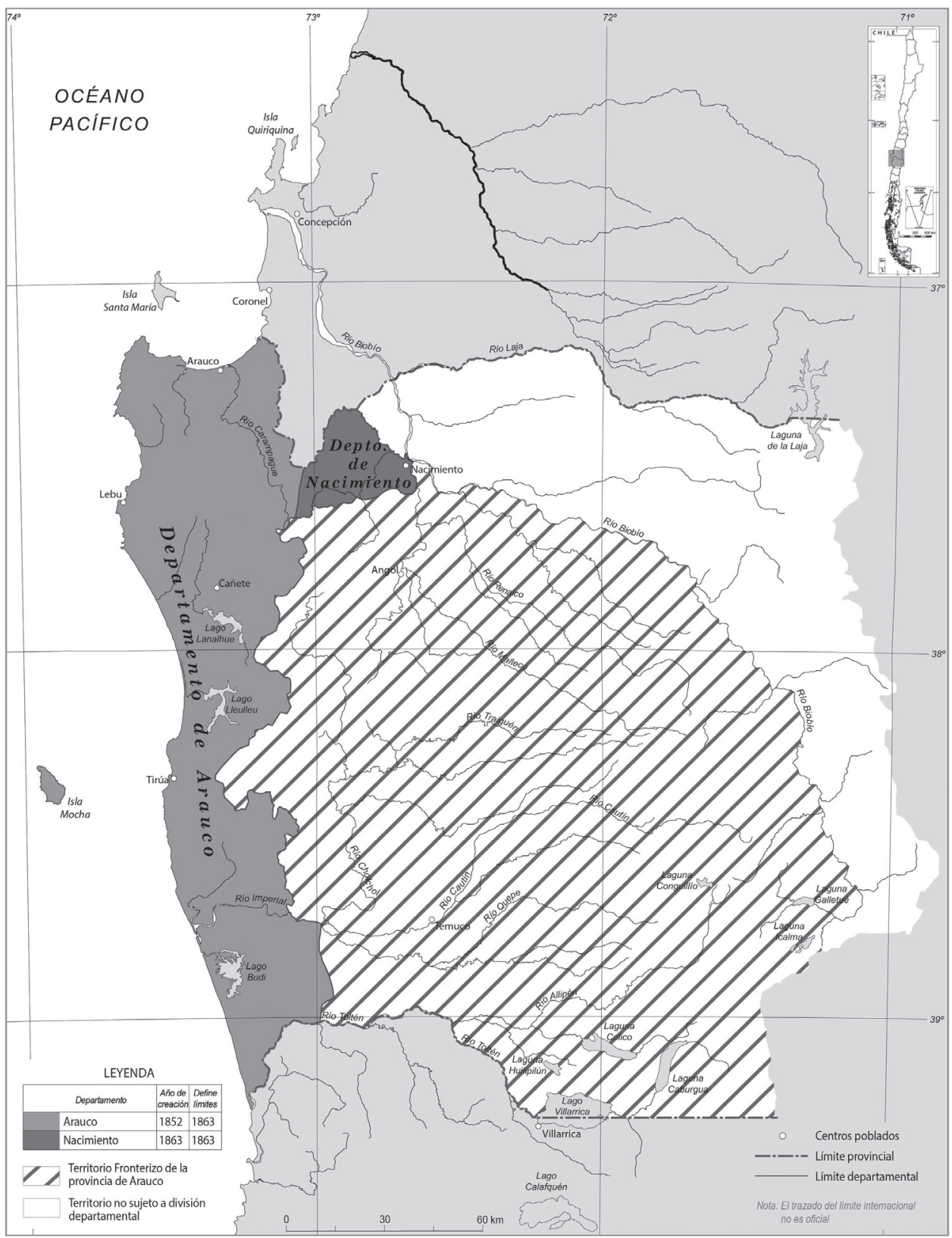

Fuente: Proyecto FONDECYT 1051034. 
Figura $\mathrm{N}^{\circ} 4$

A fines de la década de 1860 la provincia de Arauco se encuentra completamente subdivida en departamentos.

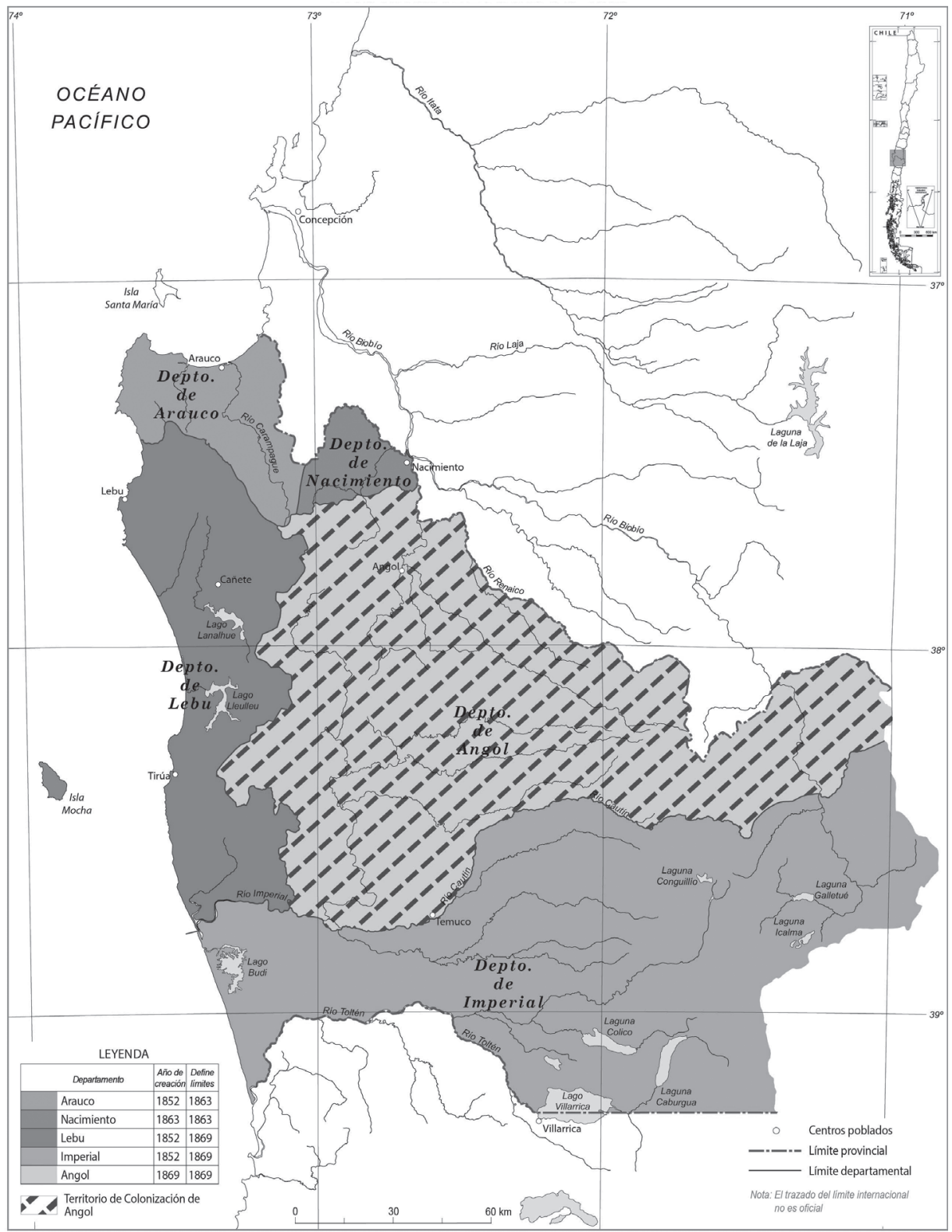

Fuente: Proyecto FONDECYT 1051034. 
Figura $N^{\circ} 5$

Provincias de Biobío y Arauco rodeando por el norte, oeste y sur al Territorio de Colonización de Angol, el que disminuyó su superficie respecto al Territorio Fronterizo de la Provincia de Arauco, como consecuencia de la conquista y colonización de La Araucanía (1875).

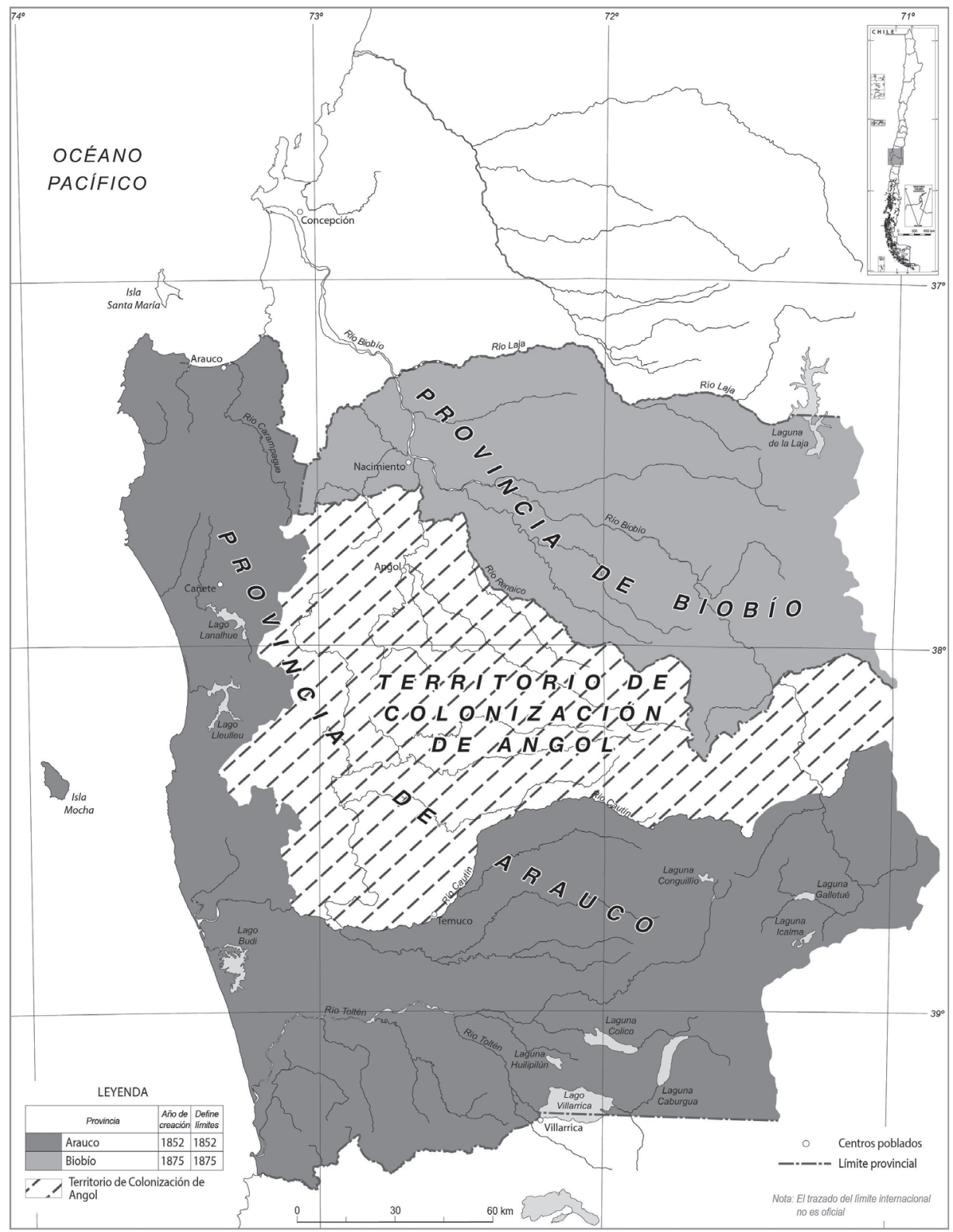

Fuente: Proyecto FONDECYT 1051034. 
que se añadió el de Nacimiento, que había sido creado en 1863, formando parte en ese entonces de la provincia de Arauco. A su vez, la provincia de Arauco quedó compuesta por los departamentos de Arauco, Lebu e Imperial, creados en 1863, 1869 y 1869, respectivamente, a los que se incorporó el de Cañete en 1875 (Figura $\mathrm{N}^{\circ}$ 6).

En definitiva, hacia fines de 1875 se había logrado avanzar por el centro de La Araucanía hasta el río Renaico; por el litoral, se había ocupado también el espacio comprendido entre la cordillera de Nahuelbuta y la costa y, por el sur, la ocupación era efectiva hasta el río Mehuín, el curso medio y superior del río Cruces que nace en el lago Villarrica y la unión de este con la cordillera andina. Por otro lado y como consecuencia de los avances logrados, se redujo también la superficie del Territorio Fronterizo de la Provincia de Arauco, quedando este con una forma semejante a un triángulo, cuya base es la cordillera de Nahuelbuta y sus lados definidos por el río Renaico por el norte y Cautín por el sur, área que corresponde administrativamente

Figura $\mathrm{N}^{\circ} 6$

Subdivisión departamental de las provincias de Arauco y Biobío en 1875. La primera está compuesta por los departamentos de Nacimiento, Laja y Mulchén y la segunda, por los de Arauco, Lebú, Cañete e Imperial.

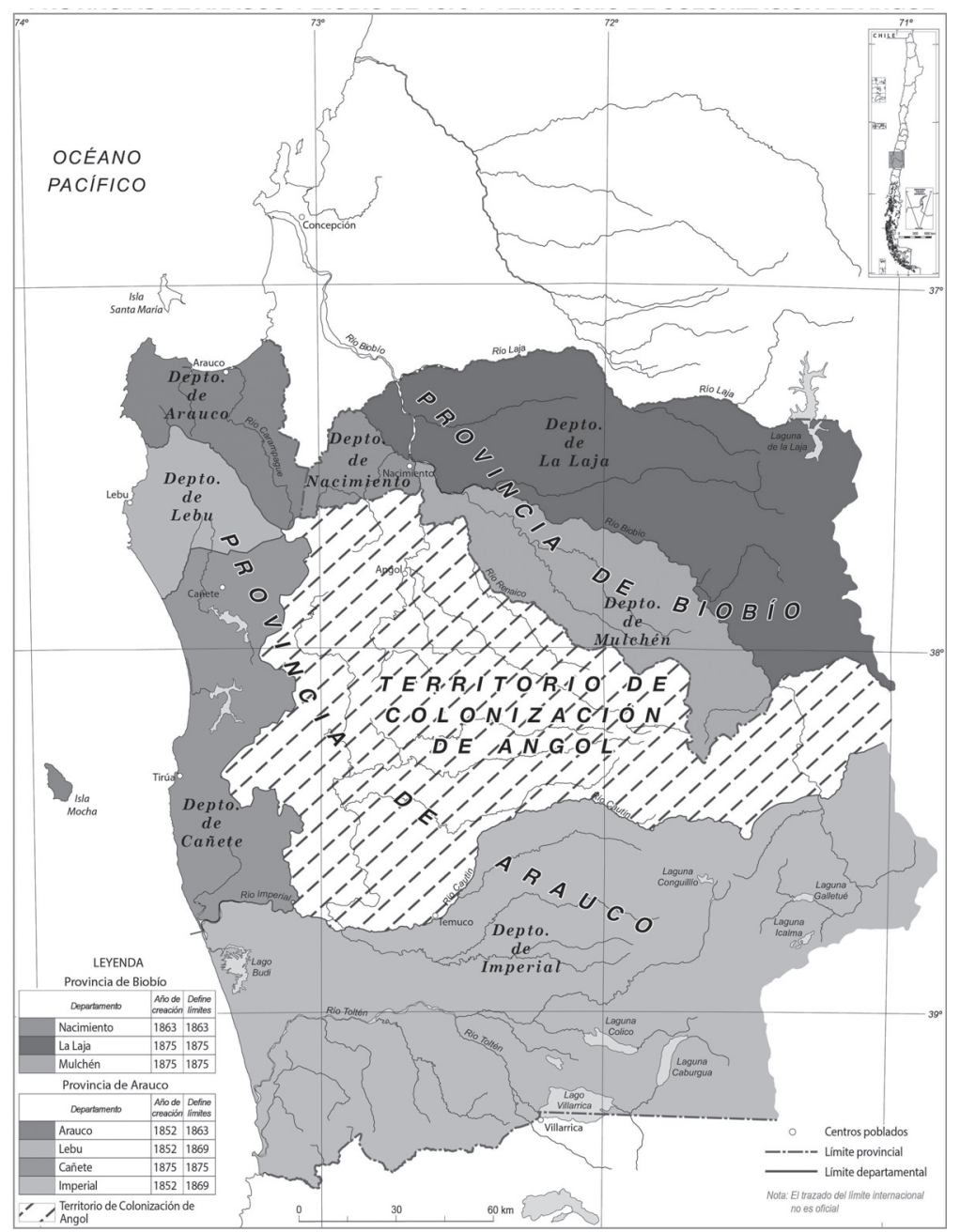

Fuente: Proyecto FONDECYT 1051034. 
al departamento de Angol, pero que por su estatus jurídico se le denomina Territorio de Colonización de Angol, muestra inequívoca del "cerco" al que se sometió el primitivo Territorio Fronterizo de la Provincia de Arauco, como producto de la implementación de la política de ocupación y colonización del gobierno central. Cabe señalar que para la administración del territorio de Angol se dispuso de un estatuto particular, donde se señaló que dependía directamente del Ministerio de Relaciones Exteriores, medida que tuvo como propósito facilitar el asentamiento de colonos extranjeros (Andreucci, 1998).

\section{De territorio de colonización a provincia}

Tras la toma de la ciudad de Villarrica por parte del coronel Gregorio Urrutia en 1883, se dio por concluido el proceso de conquista de La Araucanía. En virtud de ello, el gobierno de Domingo Santa María puso en marcha un ambicioso plan de obras públicas, que incluyó construcción de caminos, tendido de líneas de ferrocarril y telegráficas, fundación de ciudades y creación de escuelas ${ }^{10}$. Asimismo, para garantizar el ejercicio de la soberanía del Estado chileno en el territorio recién conquistado, se reguló el intercambio comercial y se mantuvo el estado de excepción del régimen jurídico en la zona. En función de lo anterior, se dio inicio al fomento de la colonización en el territorio de La Araucanía y la extensión del régimen provincial en este, lo que se reflejó, en la creación de las provincias de Malleco y Cautín en 1887, durante la presidencia de José Manuel Balmaceda.

Estas dos nuevas provincias ocuparon el área que en su momento correspondió al Territorio de Colonización de Angol, más el sector norte del Departamento de Imperial de la provincia de Arauco; es decir, ambas provincias se emplazaron desde el río Renaico por el norte hasta el río Toltén por el sur. La provincia de Malleco quedó enmarcada por el río Renaico por el norte y el río Cautín por el sur, siendo su capital Angol y la provincia de Cautín se emplazó entre el río Cautín por el norte y el río Toltén por el sur, cuya capital

10 Al respecto, ver Flores Chávez (2012). fue establecida en la ciudad de Temuco (Figura $\mathrm{N}^{\circ} 7$ ).

Con la creación de las provincias de Malleco y Cautín el país dispuso de un total de 22 provincias y un territorio, el de Magallanes.

Al mismo tiempo y con el propósito de hacer efectiva una única política administrativa en el país, se subdividieron las nuevas provincias en departamentos: la provincia de Malleco quedó conformada por los departamentos de Collipulli y Traiguén, creados junto con la provincia en 1887, a los que se agregó el de Angol, creado en 1869. En tanto, la provincia de Cautín quedó dividida en los departamentos de Temuco, creado en 1887, y el de Imperial, que se había creado en 1869 (Figura $\mathrm{N}^{\circ} 8$ ).

\section{La instalación de inmigrantes europeos en el territorio}

Mientras avanzaba el proceso de incorporación y ordenamiento del territorio de La Araucanía, en 1874 el gobierno promulgó una nueva ley de inmigración, cuyo objetivo central era favorecer el poblamiento de la zona con europeos de diversas nacionalidades. Debido a que este cuerpo legal no resultó exitoso en la medida que entregó la tarea de traer colonos a organizaciones privadas, el gobierno decidió manejar la situación de manera directa. Para ello se creó en 1882 la "Agencia General de Colonización e Inmigración para Europa", con asiento en París y Burdeos, y con sucursales en Inglaterra, Bélgica, Suiza, Holanda, Alemania e Italia.

La misión de la Agencia estatal fue organizar directamente la venida de inmigrantes a los territorios de La Araucanía, así como generar campañas de propaganda para mostrar las ventajas que el gobierno otorgaba a quienes optaran por emigrar a Chile.

A diferencia del proceso de inmigración que se había efectuado a fines de la década de 1840 y comienzos de la de 1850 en la zona de Valdivia y posteriormente de Llanquihue, que se concentró en inmigrantes de origen alemán, el que se comenzó a desarroIlar en La Araucanía tuvo un carácter plurinacional. La razón de este cambio se debió 
Figura $\mathrm{N}^{\circ} 7$

Provincias de Malleco y Cautín creadas en 1887 ocupando la totalidad del Territorio de Colonización de Angol de 1875, entendiéndose hasta el río Toltén por el sur.

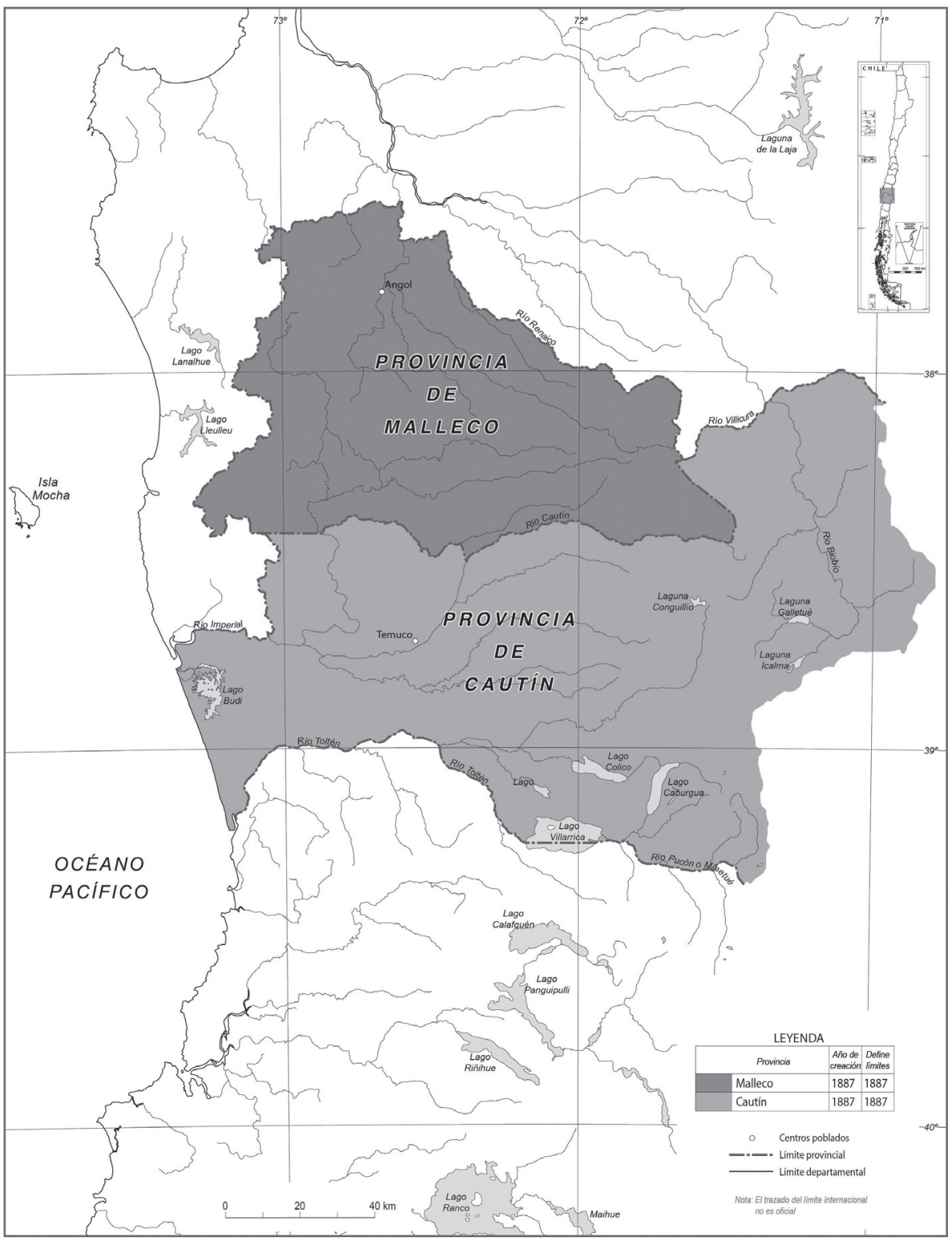

Fuente: Proyecto FONDECYT 1051034. 
Figura $\mathrm{N}^{\circ} 8$

Subdivisión de las provincias de Malleco y Cautín en departamentos, luego de su creación en 1887.

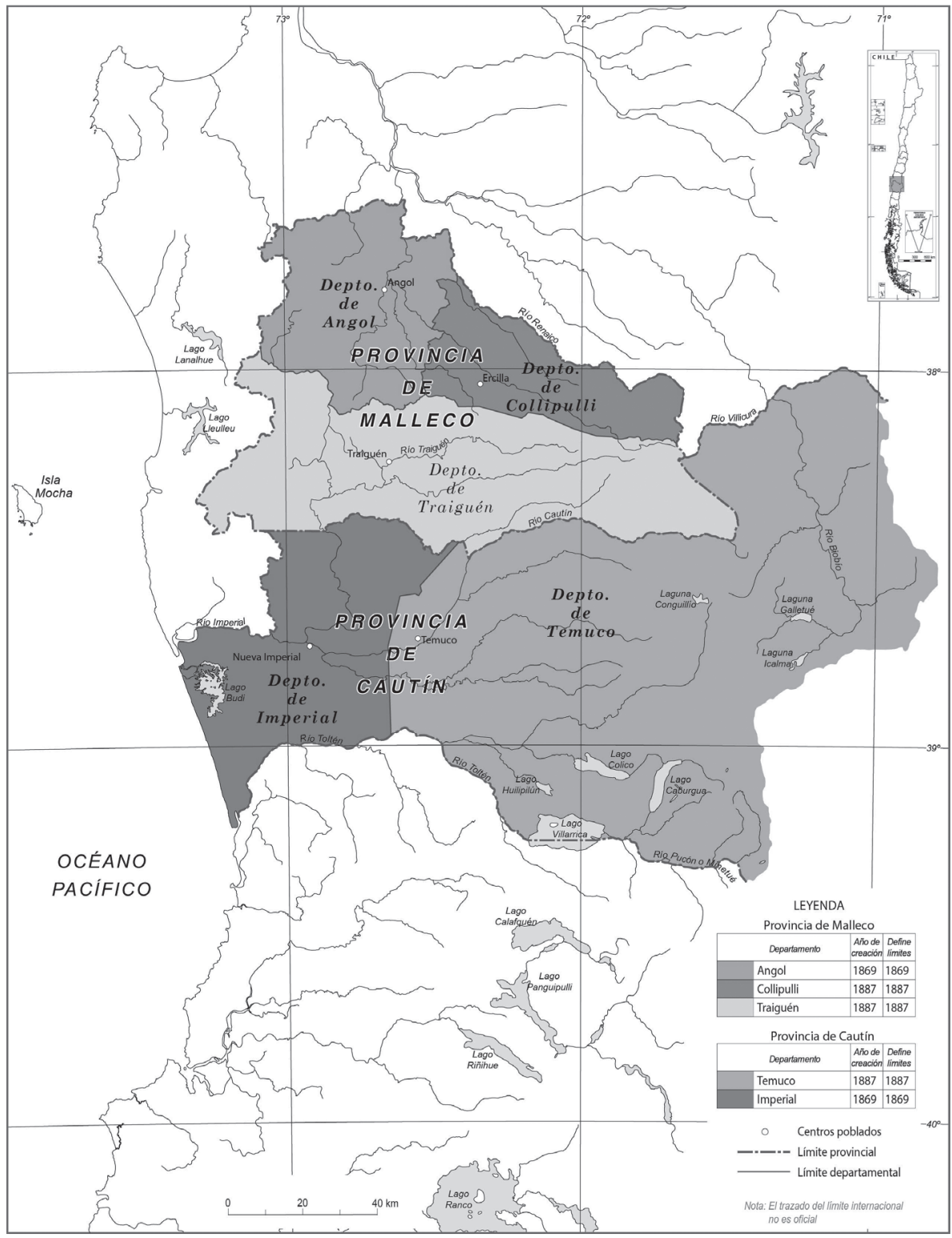

Fuente: Proyecto FONDECYT 1051034. 
fundamentalmente a que en un contexto de despliegue del imperialismo de las potencias europeas, se consideró una ventaja la mezcla de nacionalidades en la colonización de ese territorio, pues ello evitaría la posibilidad de que se fueran formando centros aislados de colonos de una sola nacionalidad, que al no integrarse a la vida nacional, se transformarían eventualmente en colonias que representarían los intereses de su país de origen.

Otra razón para traer extranjeros al territorio de La Araucanía se debió a que en esa época Argentina, país con el que había en momento agudas controversias limítrofes, había comenzado un exitoso proceso de inmigración extranjera plurinacional, que amenazaba el equilibrio demográfico con Chile. Por ello, más que favorecer un tipo específico de nacionalidad, las autoridades intentaron privilegiar la cantidad de inmigrantes.

Asimismo, la instalación de estos colonos buscó integrar las fértiles tierras de la región al sistema capitalista de explotación agrícola, en base al desarrollo de un sistema de pequeña y mediana propiedad, que se integraría posteriormente al mercado del Chile central, especialmente a través del ferrocarril ${ }^{11}$.

En función de lo anterior, la Agencia de Colonización, entre 1883 y 1890, logró que aproximadamente unos 35.000 inmigrantes europeos, entre los que se contaban franceses, italianos, suizos y alemanes, llegaran a Chile y que un poco más de 6.000 se instalaran en las distintas localidades recientemente fundadas en La Araucanía, tales como Ercilla, Contulmo, Galvarino, Lautaro, Temuco, Traiguén y Victoria (Bernedo, 1995).

Un ejemplo de la instalación de colonos europeos en la zona puede apreciarse en el Cuadro $\mathrm{N}^{\circ} 1$ :

\footnotetext{
11 Una evaluación crítica de los resultados de esta modalidad de explotación agrícola se puede consultar, entre otros, en Bengoa (1988: 251 y siguientes).
}

Cuadro $\mathrm{N}^{\circ} 1$

Distribución por localidades de colonos europeos en La Araucanía, en 1890

\begin{tabular}{|l|r|}
\hline Localidad & Número de inmigrantes \\
\hline Ercilla & 621 \\
\hline Galvarino & 367 \\
\hline Imperial & 65 \\
\hline Lautaro & 349 \\
\hline Purén & 97 \\
\hline Quechereguas & 597 \\
\hline Quillén & 309 \\
\hline Quino & 761 \\
\hline Temuco & 167 \\
\hline Traiguén & 245 \\
\hline Victoria & 1.517 \\
\hline Total & 5.254 \\
\hline
\end{tabular}

Fuente: "Colonización Nacional", en Boletín de la Sociedad de Fomento Fabril, 7/1890, p. 294, citado en Bernedo (1995: 177).

A los grupos de colonos extranjeros traídos por la Agencia de Colonización se les fueron incorporando importantes contingentes de chilenos procedentes del sur y de la zona central. De esta manera, tras un complejo proceso de ocupación de La Araucanía, el Estado de Chile logró ir imponiendo su soberanía en la zona, partiendo por darle a esta una estructura provincial y departamental, lo que fue seguido por el desarrollo de obras públicas y de un régimen especial de administración, para a continuación iniciar un proceso de colonización del territorio con inmigrantes extranjeros.

Aunque no es materia de este trabajo, sí es preciso señalar brevemente que la región fue integrándose con gran dinamismo a la vida nacional, especialmente por su alta productividad agrícola y ganadera. Sin embargo, mientras chilenos y extranjeros lograron salir adelante con sus distintos trabajos y emprendimientos, los mapuches fueron quedando rezagados en este proceso de expansión, afectados, entre otros aspectos, por la deficiente calidad de las tierras en que fueron instalados; la escasa ayuda estatal que recibieron y 
también por la enorme brecha educacional y de ingresos que se fue generando con sus nuevos vecinos.

\section{Conclusiones}

La forma como el Estado ejerce su poder sobre el territorio puede tomar diversas formas. Una de ellas es la implementación de un determinado sistema para su administración, lo que se conoce como "gobierno interior de la nación".

Chile, desde los inicios de la república, se inclinó por el modelo provincial, del cual un sector del país, La Araucanía, se mantuvo al margen por largo tiempo. En el momento que se decidió incorporarla a este modelo, pasó a constituirse en la provincia de Arauco, acontecimiento que tuvo lugar en 1852. Sin embargo, una parte del territorio bajo su jurisdicción requirió de un estatus jurídico especial, debido a que su población originaria se mostraba reacia a aceptar las normas legales que le imponía el gobierno central. Por ello, una parte de la provincia fue consignada con el nombre de Territorio Fronterizo de la Provincia de Arauco, área que se extendió entre los ríos Biobío por el norte y el Toltén por el sur. Esta zona debió ser conquistada y ocupada mediante la ejecución de un plan apoyado por el ejército, proceso que culminó con la creación de las nuevas provincias de Malleco y Cautín en 1887.

En la medida que el ejercicio de la soberanía del Estado chileno en La Araucanía se fue asentando, se dio inicio a un proceso de colonización del territorio con inmigrantes europeos, tarea que fue organizada por el gobierno central a través de la "Agencia General de Colonización e Inmigración para Europa", creada para tales efectos en 1882. Asimismo, numerosos contingentes de población chilena, procedentes de diversas zonas del país, se fueron sumando a la colonización de esta área.

En definitiva, este territorio fue sufriendo profundas transformaciones político administrativas en el tiempo y en el espacio, como ha quedado en evidencia al observar las distintas cartas temáticas expuestas.
Todo este proceso de cambios impulsado desde el gobierno central se desarrolló en un marco histórico, que nos permitió dejar en evidencia las distintas motivaciones políticas, económicas, militares y sociales que lo fueron caracterizando en distintos momentos.

La ocurrencia de un proceso histórico como el señalado anteriormente, es comúnmente expuesto por los historiadores mediante un relato, pero, dado que se trata de un fenómeno que ocurrió en un cierto espacio, en un lapso determinado, de modo dinámico y con una dimensión cualitativa y cuantitativa, cumple con todas las condiciones necesarias para un excelente empleo de la cartografía temática. Por ello, estimamos que resulta fundamental recurrir a ella no solo por su valor como registro de información y soporte comunicacional, sino que principalmente porque constituye una excelente herramienta para el análisis, comprensión y síntesis de un proceso histórico con una profunda raíz geográfica, como fue el de la incorporación del territorio de La Araucanía.

\section{Referencias bibliográficas}

ANDREUCCI, R. La incorporación de las tierras de Arauco al Estado de Chile y la posición iusnaturalista de la Revista Católica. Revista de Estudios Históricosjurídicos, 1998, №20. Disponible en Internet: http://www.scielo.cl/scielo.php?script=sci arttext\&pid=S0716-54551998000200002\&ln $\mathrm{g}=\mathrm{es} \& \mathrm{nrm}=\mathrm{iso}$

BENGOA, J. Historia social de la agricultura chilena. Tomo I. El poder y la subordinación. Santiago de Chile: Ediciones Sur, 1988.

BENGOA, J. Historia del pueblo mapuche (siglos XIX y XX). Santiago de Chile: Ediciones Sur, 1996.

BERNEDO, P. Bürgertum und Modernisierungsansätze in Chile im 19. Jahrhundert. Eichstätt: Katholische Universität Eichstätt, Tesis doctoral, 1995.

ERRÁZURIZ, A.M. et al. Cartografía Temática. Santiago de Chile: Ediciones Universidad Católica de Chile, 1988. 
FLORES CHÁVEZ, J. La Araucanía y la construcción del sur de Chile, 1880-1950. Turismo y vías de transporte. Scripta Nova. Revista Electrónica de Geografía y Ciencias Sociales, 2012, Vol. XVI, No 418 (12). Disponible en Internet: http://www.ub.es/geocrit/sn/ sn-418/sn-418-12.htm

GONZÁLEZ LEIVA, J.I. Las funciones de la Cartografía en los estudios geográficos. Revista de Geografía Norte Grande, 1986, № 13, p. 21-27.

GONZÁLEZ LEIVA, J.I. Primeros levantamientos cartográficos generales de Chile con base científica: los mapas de Claudio Gay y Amado Pissis. Revista de Geografía Norte Grande, 2007, №38, p. 21- 44.

GREVE, E. Don Amado Pissis y sus trabajos geográficos en Chile. Santiago de Chile: Imprenta Universitaria, 1946.

JOLY, F. La Cartografía. Barcelona: Ariel, 1979.

NOGGLER, A. Cuatrocientos años de misión entre los araucanos. Padre Las CasasTemuco: Editorial San Francisco, 1982.

NÚÑ̃Z, A. La formación y consolidación de la representación moderna del territorio de Chile: 1700-1900. Santiago de Chile: Pontificia Universidad Católica de Chile, Tesis doctoral, 2009.

PARENTINI, L. y HERRERA, P. Araucanía Maldita: Su imagen a través de la prensa, 1820-1860. En: LEÓN, L.; HERRERA, P.; PARENTINI, L. y VILLALOBOS, S. La Araucanía: La Frontera Mestiza, Siglo XIX. Santiago de Chile: UCSH, 2003, p. 63-100.

PARENTINI, L. y HERRERA, P. Los afuerinos y su impacto en la penetración de Araucanía, 1860-1883. En: LEÓN, L.; HERRERA, P.; PARENTINI, L. y VILLALOBOS, S. La Araucanía: La Frontera Mestiza, Siglo XIX. Santiago de Chile: UCSH, 2003, p. 101-179.
PINTO, J. La formación del Estado y la Nación, y el pueblo Mapuche. Santiago de Chile: Ediciones DIBAM-Centro de Investigaciones Diego Barros Arana, 2003.

RAVEST, M. Arauco...Siempre Arauco... (Estudio Introductorio). Documentos Relativos a la Ocupación de Arauco de Cornelio Saavedra. Santiago de Chile: Biblioteca Fundamentos de la Construcción de Chile, N ${ }^{\circ}$ 43, 2009, p. IX-LIX.

SAAVEDRA, C. Extracto de las sesiones de la Cámara de Diputados sobre la cuestión de Arauco. Documentos relativos a la ocupación de Arauco. Santiago de Chile: Colección Biblioteca Fundamentos de la Construcción de Chile, CChC-PUC-BN, 2008, Anexo E, p. 371-377.

SANHUEZA, M. C., La primera división política administrativa de Chile, 1811-1826. Historia, 2008, Vol. II, N 41, p. 447-493.

STUARDO, C. Vida de Claudio Gay. Escritos y Documentos. Santiago de Chile: Fondo Histórico y Bibliográfico José Toribio Medina, Nascimento, 1975.

VARAS, A. Informe presentado a la Cámara de Diputados por don Antonio Varas, visitador judicial de la República, en cumplimiento del acuerdo celebrado en la sesión del 20 de diciembre del año de 1848, sobre la reducción pacífica del territorio araucano. En: SAAVEDRA, C. Documentos relativos a la ocupación de Arauco. Santiago de Chile: Colección Biblioteca Fundamentos de la Construcción de Chile, CChC-PUC-BN, 2008, p. 267-321.

VILLALOBOS, S. Tres siglos y medio de vida fronteriza. En: VILLALOBOS, S.; ALDUNATE, C.; ZAPATER, H.; MÉNDEZ, L. y BASCUÑÁN, C. Relaciones fronterizas en La Araucanía. Santiago de Chile: Ediciones Universidad Católica, 1982. 